\title{
What is the Minimal Surgery for Papillary Thyroid Carcinoma?
}

\author{
Eran Fridman, M.D., and Ziv Gil, M.D.* \\ Department of Otolaryngology Head and Neck Surgery, The Head and Neck Center, the Clinical Research \\ Institute, Rambam Health Care Campus, Rappaport Institute of Research and Medicine, The Technion- \\ Israel Institute of Technology, Haifa, Israel
}

\begin{abstract}
Although thyroid surgery for treatment of papillary thyroid carcinoma (PTC) has been practiced for more than 100 years, there is still controversy regarding the minimal surgery needed for cure. The main reason for this controversy is lack of prospective randomized trials. The data accumulated in the last four decades indicate that hemithyroidectomy can be sufficient and safely practiced in low-risk patients with PTC. Patients $<45$ years of age with a single tumor less than $2 \mathrm{~cm}$, with no lymphatic spread, and in the absence of other risk factors, can be equally managed by hemithyroidectomy or total thyroidectomy. A slight increase in the risk of vocal cord paralysis and hypocalcemia after total thyroidectomy suggests that hemithyroidectomy is appropriate for the management of patients with stage T1 disease. Any choice regarding the extent of surgery should be made with the patient and his family and in a multidisciplinary setup, which has been shown to improve decision-making procedures before the operation and during follow-up.
\end{abstract}

KEY WORDS: Hemithyroidectomy, lobectomy, papillary, thyroid

\section{INTRODUCTION}

Thyroid cancer incidence has tripled over the last three decades, from 4.9 to 14.3 per 100,000 people. This is almost exclusively due to an increase in the

incidence of early-stage papillary thyroid carcinoma (PTC), from 3.4 to 12.5 per 100,000 people. ${ }^{1}$ Nevertheless, the increase in diagnosis of early-stage

\footnotetext{
Abbreviations: DSS, disease-specific survival; NCDB, National Cancer Data Base; OS, overall survival; PTC, papillary thyroid carcinoma; RAI, radioactive iodine.

Citation: Fridman E, Gil Z. What is the Minimal Surgery for Papillary Thyroid Carcinoma?. Rambam Maimonides Med J 2016;7 (1):eooo5. doi:10.5041/RMMJ.10232 Review

Copyright: (C) 2016 Fridman and Gil. This is an open-access article. All its content, except where otherwise noted, is distributed under the terms of the Creative Commons Attribution License (http://creativecommons.org/licenses/by/3.o), which permits unrestricted use, distribution, and reproduction in any medium, provided the original work is properly cited.

Conflict of interest: No potential conflict of interest relevant to this article was reported.

* To whom correspondence should be addressed. E-mail: ziv@baseofskull.org
} 
PTC did not decrease the mortality from this disease, which has remained unchanged during this period. ${ }^{1,2}$ The increase in surgeries for resection of $<2 \mathrm{~cm}$ PTC is considered to be mainly due to the accessibility of high-resolution ultrasound and the increase in use of routine imaging modalities of the neck for other diseases. ${ }^{2-4}$ In agreement with the utility of imaging modalities, the number of more advanced PTC diagnosed has also increased. 5 Papillary thyroid carcinoma has generally a better outcome compared to other thyroid cancer types, with a 5 -year overall survival (OS) of $97 \%-99 \%{ }^{6}$ Nevertheless, there is a subset of patients that face a worse prognosis, and it is important to recognize and distinguish these patients in order to provide adequate treatment that can improve outcome.

A number of staging systems have been suggested in order to distinguish between low- and highrisk patients. The Mayo Clinic offered the MACIS system (metastasis, age, completeness of resection, invasion, and size), 7 while the Memorial SloanKettering Cancer Center divided patients to low-, intermediate-, and high-risk patients using age, the presence of distant metastasis, tumor size, and histology. Both systems found excellent survival rates for low-risk patients, which represent $>80 \%$ of the patients, with a 5 -year OS of $100 \%$ and a 20 -year OS of $99 \% .{ }^{8-10}$ In accordance with these systems, the American Joint Committee on Cancer (AJCC) published a TNM staging system which takes into account several risk factors including patient age, tumor size, histopathological type, status of lymph nodes, and presence of distant metastasis. ${ }^{11}$

In all of these staging systems, the cutoff size for T1 classification is tumor size $<2 \mathrm{~cm}$. This distinction emerged since the survival rate for tumors $<2 \mathrm{~cm}$ is $\sim 99 \% .^{10}$

Since the beginning of the twentieth century, surgery has remained the main modality of treatment for PTC. ${ }^{12}$ Although thyroid surgery has been practiced for more than 100 years, there is still controversy regarding the minimal surgery for treatment of PTC. In this paper we will describe the factors which influence the decision regarding the extent of thyroid surgery in patients with low-risk PTC.

\section{THE EXTENT OF THYROID SURGERY}

The goals of treatment of patients with low-risk PTC are: to improve overall survival, to reduce the rate of recurrence, and to minimize complications. The main reason for the controversy of the minimal surgery for PTC is the lack of prospective randomized studies. Since the biology of this slow-growing disease will require large cohorts of patients and very long follow-up, such studies are not expected any time soon.

Although the American Thyroid Association and the National Cancer Comprehensive Network recommended that patients with $<1 \mathrm{~cm}$ PTC should undergo hemithyroidectomy in the absence of contralateral nodes, lymphatic spread, and distant metastases, there are still clinicians that would perform total thyroidectomy on low-risk patients. Another disagreement is regarding the surgical treatment of low-risk patients with tumors sized 1-4 $\mathrm{cm}$.

Since 1940 there has been a sharp decline in the number of patients undergoing hemithyroidectomy. However, since 1985, the pendulum has shifted back to hemithyroidectomy as the modality of treatment of low-risk PTC. ${ }^{13}$ There are a number of considerations in favor of total thyroidectomy: it enables the use of radioactive iodine (RAI) after surgery, patients can be treated with thyroid-stimulating hormone (TSH) suppression, and follow-up can be easily and inexpensively performed using thyroglobulin measurement. It also minimizes the risk of leaving tumor tissue behind, in cases of multifocal and bilateral disease.

Total thyroidectomy, which requires the removal of all thyroid tissue, puts at higher risk recurrent and superior laryngeal nerve, and the parathyroid glands and their vascular supply, compared to hemithyroidectomy, which involves removal of one lobe only. ${ }^{14}$ As a result, the complication rate is significantly higher in the case of total thyroidectomy. Kandil et al. conducted a meta-analysis, examining 50,445 patients who underwent thyroid surgery (30\% hemithyroidectomy versus $70 \%$ total thyroidectomy). They reported a higher relative risk (RR) for all complications in the total thyroidectomy group. ${ }^{15}$ Specifically, the RR was 10.67 for temporary hypocalcemia, 3.17 for permanent hypocalcemia, 1.69 and 1.89 for temporary and permanent injury to the recurrent laryngeal nerve, and 2.58 for hemorrhage. Another potential disadvantage of total thyroidectomy is the need for lifelong thyroid hormone replacement. The need for long thyroid hormone replacement in patients undergoing hemithyroidectomy was estimated in a recent meta-analysis of 4,899 patients. ${ }^{16}$ The weighted pooled incidence of hypothyroidism after hemithyroidectomy was 
$21 \%$ (95\% CI 17-25), but only 4\% (95\% CI 2-8) had symptoms as a result.

The prognosis of patients with PTC $<1 \mathrm{~cm}$ (also known as microcarcinoma) is excellent, and most guidelines recommend hemithyroidectomy for these tumors in the absence of the following risk factors: lymphatic spread, distant metastases, past radiation, macroscopic multifocal disease, or extra-capsular extension. ${ }^{17}$ Only the Latin American Thyroid Society recommends total thyroidectomy for all PTC regardless of size. ${ }^{18}$ Lately several authors have been arguing for an even more conservative approach towards PTC. This approach was first suggested by Ito et al. who followed 340 patients with $\mathrm{PTC}<1 \mathrm{~cm}$. Of these, 109 (32\%) underwent surgery during the observation period with no effect on nodal metastasis. ${ }^{19}$ The authors concluded that surveillance instead of surgery is an accepted modus operandi. Similarly Castro at al. from the Mayo Clinic support this view. ${ }^{20}$ In a report of 1,465 from two different groups (who were followed using the active surveillance approach which included ultrasound at 6 months and then once a year), during an average of 75 months of follow-up only $14 \%$ had surgery, and there was no disease-specific mortality. ${ }^{21,22}$

\section{THE CONTROVERSY OVER THE BILIMORIA STUDY}

The largest study that showed survival benefit for patients undergoing total thyroidectomy was by Bilimoria et al. ${ }^{23}$ They used the National Cancer Data Base (NCDB) and conducted analysis of 52,173 patients recruited from multiple centers in the United States. The conclusion of the authors was that total thyroidectomy for PTC $>1 \mathrm{~cm}$ is associated with better outcome, in terms of recurrence and OS. The data influenced future guidelines of several societies; however, re-evaluation of the data from this study raised significant concerns regarding the validity of their conclusions. First, when examining the patient characteristics, one can see that 761 (10.5\%) of patients that had hemithyroidectomy had nodal disease prior to surgery. This means the extent of the initial surgery was inadequate. Second, $723(18.4 \%)$ of the patients that were reported to undergo hemithyroidectomy also received adjuvant RAI. This piece of data questions the validity of the database which the study is based on. It also suggests the initial surgery was inadequate. Third, the overall difference between hemithyroidectomy and total thyroidectomy when including all comers, in terms of 20 year survival, is $\sim 1 \%$, also when including patients with $>4 \mathrm{~cm}$ tumors. This finding suggests that statistical differences which are frequently found in large cohorts have minimal clinical significance. Shah ${ }^{24}$ and Yu et al. ${ }^{25}$ have also raised some limitations and opt for careful drawing of conclusions and making of recommendations based on Bilimoria's data. Adam et al. ${ }^{6}$ used the same database (NCDB), analyzing 61,775 patients, with tumor size of 1-4 cm, who underwent total or hemithyroidectomy. They found no difference in OS between the two groups. Table 1 lists articles demonstrating that hemithyroidectomy is an adequate surgery compared to total thyroidectomy in terms of measured outcome.

\section{THE ROLE OF POSTOPERATIVE RAI TREATMENT}

The follow-up of patients with low-risk PTC includes periodical physical examination, ultrasound, and monitoring of TSH, anti-thyroglobulin $\mathrm{Ab}$, and thyroglobulin levels. The last-mentioned is significant only after total thyroid resection and RAI therapy. Postoperative RAI treatment can improve locoregional control in high-risk patients; however, it has no impact on outcome of patients with stage I disease. The use of RAI is also used for ablation of residual thyroid tissue and for imaging for metastatic or recurrent disease. Podnos et al. have reported that only high-risk patients (age $>45$, tumor size $>2 \mathrm{~cm}$, presence of lymph node metastases and distant metastases) benefit from postoperative RAI. ${ }^{6}$ In a review on the role of postoperative RAI, Patel and Goldfarb have summarized that for the low-risk patients there is no outcome benefit using RAI. ${ }^{37}$ Mendelsohn et al. have found better OS for patients treated with RAI but decreased disease-specific survival (DSS). ${ }^{31}$ In the recently published 2015 American Thyroid Association Management Guidelines for Adult Patients with Thyroid Nodules and Differentiated Thyroid Cancer, the authors conclude that there is no benefit of RAI treatment in patients with low-risk PTC.12 One should also bear in mind the frequent adverse effects of RAI which involves dysgeusia, salivary gland inflammation, $3^{8}$ and an increase in the risk of salivary gland malignancies and leukemia. 39

\section{MULTIFOCAL PAPILLARY CARCINOMA}

Multifocal disease is two or more distinct PTC lesions found on a specimen. It can arise from the same tumor (same clone) or a second primary PTC. 40 Those who side for total thyroidectomy 
Table 1. Data Showing that Hemithyroidectomy Is Equal to Total Thyroidectomy in Terms of Measured Outcome.

\begin{tabular}{|c|c|c|c|c|}
\hline Author & Year & $n$ & Database/Institute & Conclusion \\
\hline Shaha AR, et al. ${ }^{26}$ & 1997 & 1,038 & $\begin{array}{l}\text { Memorial Sloan- } \\
\text { Kettering Cancer } \\
\text { Center, New York, USA }\end{array}$ & $\begin{array}{l}\text { No statistical difference in local } \\
\text { recurrence rate, overall failure } \\
\text { rate }\end{array}$ \\
\hline Wanbeo $\mathrm{H}$, et al. ${ }^{27}$ & 1998 & 347 & $\begin{array}{l}\text { Brown University, } \\
\text { Providence, Rhode } \\
\text { Island, USA }\end{array}$ & $\begin{array}{l}\text { Total is equal to } \\
\text { hemithyroidectomy in high-risk } \\
\text { patients with differentiated thyroid } \\
\text { cancer (follicular histology, } \\
\text { vascular invasion, or extra-capsular } \\
\text { extension) }\end{array}$ \\
\hline Hundahl SA, et al. ${ }^{28}$ & 1998 & 53,856 & NCDB & $\begin{array}{l}\text { Extent of surgery has no impact on } \\
\text { survival in any subgroup } \\
\text { of papillary or follicular carcinoma }\end{array}$ \\
\hline Haigh PI, et al. ${ }^{29}$ & 2005 & 5,432 & SEER & $\begin{array}{l}\text { No difference in outcome between } \\
\text { groups for both low- and high- } \\
\text { risk patients }\end{array}$ \\
\hline Vorburger SA, et al. ${ }^{30}$ & 2009 & 2,867 & $\begin{array}{l}\text { Inselspital, Bern, } \\
\text { Switzerland }\end{array}$ & $\begin{array}{l}\text { No difference in outcome between } \\
\text { groups }\end{array}$ \\
\hline Mendelsohn AH, et al. ${ }^{31}$ & 2010 & 22,274 & SEER & $\begin{array}{l}\text { No differences in overall or } \\
\text { disease-specific survival }\end{array}$ \\
\hline Barney BM, et al. 32 & 2011 & 23,605 & SEER & $\begin{array}{l}\text { No difference in outcome between } \\
\text { groups }\end{array}$ \\
\hline Nixon IJ, et al. ${ }^{33}$ & 2012 & 889 & $\begin{array}{l}\text { Memorial Sloan- } \\
\text { Kettering Cancer } \\
\text { Center, New York, USA }\end{array}$ & $\begin{array}{l}\text { No difference in local recurrence } \\
\text { or regional recurrence between } \\
\text { groups }\end{array}$ \\
\hline Ebina $A$, et al. ${ }^{34}$ & 2014 & 1,187 & $\begin{array}{l}\text { Cancer Institute } \\
\text { Hospital, Tokyo, Japan }\end{array}$ & $\begin{array}{l}\text { No difference in outcome between } \\
\text { groups }\end{array}$ \\
\hline Nilubol and Kebebew ${ }^{35}$ & 2014 & 61,523 & SEER & $\begin{array}{l}\text { No difference in outcome between } \\
\text { groups }\end{array}$ \\
\hline Adam MA, et al. ${ }^{6}$ & 2014 & 61,775 & NCDB & $\begin{array}{l}\text { No difference in outcome between } \\
\text { groups }\end{array}$ \\
\hline
\end{tabular}

frequently argue that PTC is a multifocal disease irrespective of size and therefore every patient with papillary cancer should undergo total thyroid ablation. Lucchini et al. have reviewed the records of 538 patients from a single institute that had undergone total thyroidectomy. They found a prevalence of $43 \%$ multifocal disease regardless of tumor size. ${ }^{41} \mathrm{Kim}$ et al. studied 2,039 patients with PTC and concluded that multifocal disease has a prognostic value only for tumors $>1 \mathrm{~cm} . .^{22}$ However, they found no benefit of total thyroidectomy in these cases. Other studies also reported conflicting results on the risk of contralateral microcarcinoma in PTC $<1 \mathrm{~cm} .43,44$ Nevertheless, all the aforementioned studies found no difference in outcome between the extent of the resection and outcome.

\section{CONCLUSIONS}

The data on PTC accumulated in the last four decades indicate that hemithyroidectomy can be safely practiced in low-risk patients with PTC. Patients with a single nodule less than $2 \mathrm{~cm}$, age $<45$ years, without nodal metastases, and with no other risk factors can benefit from either total or hemithyroidectomy. The slight increase in the risk of vocal cord paralysis and hypocalcemia after total thyroidectomy suggests that hemithyroidectomy is appropriate for the management of patients with the stage T1NoMo classification. Any choice regarding the extent of surgery should be made with the patient and his family, in a multidisciplinary setup, which improves decision-making before the operation and the management during the long-term follow-up needed. 


\section{REFERENCES}

1. Davies L, Welch HG. Current thyroid cancer trends in the United States. JAMA Otolaryngol Head Neck Surg 2014;140(4):317-22. Full Text

2. La Vecchia C, Malvezzi M, Bosetti C, et al. Thyroid cancer mortality and incidence: a global overview. Int J Cancer 2015;136:2187-95. Full Text

3. Chen AY, Jemal A, Ward EM. Increasing incidence of differentiated thyroid cancer in the United States, 1988-2005. Cancer 2009;115:3801-7. Full Text

4. Hall SF, Walker H, Siemens R, Schneeberg A. Increasing detection and increasing incidence in thyroid cancer. World J Surg 2009;33:2567-71. Full Text

5. Morris LGT, Myssiorek D. Improved detection does not fully explain the rising incidence of welldifferentiated thyroid cancer: a population-based analysis. Am J Surg 2010;200:454-61. Full Text

6. Adam MA, Pura J, Gu L, et al. Extent of surgery for papillary thyroid cancer is not associated with survival: an analysis of 61,775 patients. Ann Surg 2014;260:601-5; discussion 605-7. Full Text

7. Hay ID, Bergstralh EJ, Goellner JR, Ebersold JR, Grant CS. Predicting outcome in papillary thyroid carcinoma: development of a reliable prognostic scoring system in a cohort of 1779 patients surgically treated at one institution during 1940 through 1989. Surgery 1993;114:1050-7; discussion 1057-8.

8. Shaha AR. Controversies in the management of thyroid nodule. Laryngoscope 2000;110:183-93. Full Text

9. Hay ID, Grant CS, Taylor WF, McConahey WM. Ipsilateral lobectomy versus bilateral lobar resection in papillary thyroid carcinoma: a retrospective analysis of surgical outcome using a novel prognostic scoring system. Surgery 1987;102:1088-95.

10. Shaha A. Treatment of thyroid cancer based on risk groups. J Surg Oncol 2006;94:683-91. Full Text

11. Edge S, Byrd DR, Compton CC, Fritz AG, Greene FL, Trotti A. AJCC Cancer Staging Manual. 7 th ed. New York, NY: Springer; 2010.

12. Haugen BR, Alexander EK, Bible KC, et al. 2015 American Thyroid Association management guidelines for adult patients with thyroid nodules and differentiated thyroid cancer. Thyroid 2016;26:1-133. Full Text

13. Hay ID, Thompson GB, Grant CS, et al. Papillary thyroid carcinoma managed at the mayo clinic during six decades (1940-1999): temporal trends in initial therapy and long-term outcome in 2444 consecu- tively treated patients. World J Surg 2002;26:87985. Full Text

14. Tuttle RM. Differentiated thyroid cancer: Surgical treatment. UpToDate website. Available at: http://bit.ly/1P5bRY4. Accessed December 29, 2015.

15. Kandil E, Krishnan B, Noureldine SI, Yao L, Tufano RP. Hemithyroidectomy: a meta-analysis of postoperative need for hormone replacement and complications. ORL J Otorhinolaryngol Relat Spec 2013;75:6-17. Full Text

16. Verloop H, Louwerens M, Schoones JW, Kievit J, Smit JWA, Dekkers OM. Risk of hypothyroidism following hemithyroidectomy: systematic review and meta-analysis of prognostic studies. J Clin Endocrinol Metab 2012;97:2243-55. Full Text

17. McLeod DSA, Sawka AM, Cooper DS. Controversies in primary treatment of low-risk papillary thyroid cancer. Lancet 2013;381:1046-57. Full Text

18. Pitoia F, Ward L, Wohllk N, et al. Recommendations of the Latin American Thyroid Society on diagnosis and management of differentiated thyroid cancer. Arq Bras Endocrinol Metabol 2009;53:884-7. Full Text

19. Ito $\mathrm{Y}$, Miyauchi $\mathrm{A}$, Inoue $\mathrm{H}$, et al. An observational trial for papillary thyroid microcarcinoma in Japanese patients. World J Surg 2010;34:28-35. Full Text

20. Castro MR, Morris JC, Ryder M, Brito JP, Hay ID. Most patients with a small papillary thyroid carcinoma enjoy an excellent prognosis and may be managed with minimally invasive therapy or active surveillance. Cancer 2015;121:3364-5. Full Text

21. Ito $\mathrm{Y}$, Miyauchi $\mathrm{A}$, Kihara $\mathrm{M}$, Higashiyama $\mathrm{T}$, Kobayashi K, Miya A. Patient age is significantly related to the progression of papillary microcarcinoma of the thyroid under observation. Thyroid 2014;24: 27-34. Full Text

22. Sugitani I, Toda K, Yamada K, Yamamoto N, Ikenaga M, Fujimoto Y. Three distinctly different kinds of papillary thyroid microcarcinoma should be recognized: our treatment strategies and outcomes. World J Surg 2010;34:1222-31. Full Text

23. Bilimoria KY, Bentrem DJ, Ko CY, et al. Extent of surgery affects survival for papillary thyroid cancer. Ann Surg 2007;246:375-81; discussion 381-4. Full Text

24. Shah JP. Re: Extent of surgery affects papillary thyroid cancer. Ann Surg 2008;247:1082-3; author reply $1083-4$. Full Text

25. Yu G-P, Schantz SP. Extent of surgery affects papillary thyroid cancer. Ann Surg 2009;249:54950; author reply 550. Full Text 
26. Shaha AR, Shah JP, Loree TR. Low-risk differentiated thyroid cancer: the need for selective treatment. Ann Surg Oncol 1997;4:328-33. Full Text

27. Wanebo H, Coburn M, Teates D, Cole B. Total thyroidectomy does not enhance disease control or survival even in high-risk patients with differentiated thyroid cancer. Ann Surg 1998;227:912-21. Full Text

28. Hundahl SA, Fleming ID, Fremgen AM, Menck HR. A National Cancer Data Base report on 53,856 cases of thyroid carcinoma treated in the U.S., 1985-1995 [see comments]. Cancer 1998;83:2638-48. Full Text

29. Haigh PI, Urbach DR, Rotstein LE. Extent of thyroidectomy is not a major determinant of survival in low- or high-risk papillary thyroid cancer. Ann Surg Oncol 2005;12:81-9. Full Text

30. Vorburger SA, Übersax L, Schmid SW, Balli M, Candinas D, Seiler CA. Long-term follow-up after complete resection of well-differentiated cancer confined to the thyroid gland. Ann Surg Oncol 2009;16:2862-74. Full Text

31. Mendelsohn AH, Elashoff DA, Abemayor E, St John MA. Surgery for papillary thyroid carcinoma: is lobectomy enough? Arch Otolaryngol Head Neck Surg 2010;136:1055-61. Full Text

32. Barney BM, Hitchcock YJ, Sharma P, Shrieve DC, Tward JD. Overall and cause-specific survival for patients undergoing lobectomy, near-total, or total thyroidectomy for differentiated thyroid cancer. Head Neck 2011;33:645-9. Full Text

33. Nixon IJ, Ganly I, Patel SG, et al. Thyroid lobectomy for treatment of well differentiated intrathyroid malignancy. Surgery 2012;151:571-9. Full Text

34. Ebina A, Sugitani I, Fujimoto Y, Yamada K. Riskadapted management of papillary thyroid carcinoma according to our own risk group classification system: is thyroid lobectomy the treatment of choice for lowrisk patients? Surgery 2014;156:1579-89. Full Text

35. Nilubol N, Kebebew E. Should small papillary thyroid cancer be observed? A population-based study. Cancer 2015;121:1017-24. Full Text
36. Podnos YD, Smith DD, Wagman LD, Ellenhorn JDI. Survival in patients with papillary thyroid cancer is not affected by the use of radioactive isotope. J Surg Oncol 2007;96:3-7. Full Text

37. Patel SS, Goldfarb M. Well-differentiated thyroid carcinoma: the role of post-operative radioactive iodine administration. J Surg Oncol 2013;107:66572. Full Text

38. Brito JP, Morris JC, Montori VM. Thyroid cancer: zealous imaging has increased detection and treatment of low risk tumours. BMJ 2013;347:f4706. Full Text

39. Iyer NG, Morris LGT, Tuttle RM, Shaha AR, Ganly I. Rising incidence of second cancers in patients with low-risk (T1No) thyroid cancer who receive radioactive iodine therapy. Cancer 2011;117:4439-46. Full Text

40. Shattuck TM, Westra WH, Ladenson PW, Arnold A. Independent clonal origins of distinct tumor foci in multifocal papillary thyroid carcinoma. N Engl J Med 2005;352:2406-12. Full Text

41. Lucchini R, Monacelli M, Santoprete S, et al. Differentiated thyroid tumors: surgical indications. G Chir 2013;34:153-7. Full Text

42. Kim KJ, Kim SM, Lee YS, Chung WY, Chang HS, Park CS. Prognostic significance of tumor multifocality in papillary thyroid carcinoma and its relationship with primary tumor size: a retrospective study of 2,309 consecutive patients. Ann Surg Oncol 2015;22:12531. Full Text

43. Pitt SC, Sippel RS, Chen H. Contralateral papillary thyroid cancer: does size matter? Am J Surg 2009;197:342-7. Full Text

44. Schindler AM, van Melle G, Evequoz B, Scazziga B. Prognostic factors in papillary carcinoma of the thyroid. Cancer 1991;68:324-30. Full Text 